\title{
ANALISIS ARUS JENUH DAN PANJANG ANTRIAN PADA SIMPANG BERSINYAL GATOT SUBROTO-VETERAN KOTA BANJARMASIN
}

\author{
Robiatul Adawiyah ${ }^{(1)}$ Tezar Aulia Rachman ${ }^{(2)}$ \\ (1),(2) Dosen Program Studi Teknik Sipil, Faktek, Universitas Islam Kalimantan MAB \\ E-mail : Awe_halis@yahoo.com/HP+6282152864455
}

\begin{abstract}
ABSTRAK
Kota Banjarmasin adalah ibu kota Propinsi Kalimantan Selatan yang merupakan kota industri dan perdaganganan. Hal ini menyebabkan pertumbuhan arus lalu lintas di daerah ini dan daerah sekitarnya meningkat dengan pesat. Pertumbuhan arus lalu lintas saat ini sering menghadapi permasalahan seiring dengan perkembangan kota, pertambahan penduduknya dan pertambahan kendaraan bermotor yang tidak sesuai bila dibandingkan dengan laju pembangunan infrastruktur jalan raya dan falisilitasnya. Simpang bersinyal Jalan Gatot Subroto - Jalan Veteran Banjarmasin merupakan dua arus lalu lintas yang terbebani arus lalu lintas yang cukup besar. Seperti pada lokasi tersebut merupakan jalan utama yang menghubungkan antara Jalan Lingkar Dalam dan Jalan A.Yani, sehingga mengakibakan kemacetan lalu lintas yang tinggi, di sisi lain pada jalan tersebut sudah sulit untuk ditingkatkan dalam pelebaran jalan dikarenakan tingkat pemukiman penduduk padat pada sisi jalan terutama terjadi pada persimpangan. Penelitian ini bertujuan untuk mendapatkan tingkat pelayanan pada persimpangan Gatot Subroto - Jalan Veteran Banjarmasin. Dari hasil perhitungan didapatkan nilai derajat kejenuhan (DS) terbesar 2,14 maka tingkat pelayanan Persimpangan Jalan Gatot Subroto - Jalan Veteran Banjarmasin termasuk level F yaitu yaitu pada tingkat ini arus lalu lintas berada dalam keadaan dipaksakan, kecepatan relatif rendah, arus lalu lintas sering terhenti sehingga menimbulkan antrian kendaraan yang panjang sebesar 1540 meter.
\end{abstract}

Kata kunci: Simpang Bersinyal, Lalu Lintas, DS, LoS

\section{ABSTRACK}

Banjarmasin City is the capital of South Kalimantan Province which is an industrial and trading city. This causes the growth of traffic flow in this area and the surrounding 
area to increase rapidly. The current growth of traffic flow often faces problems along with the development of the city, its population growth and the incremental increase in motor vehicles when compared to the pace of road infrastructure development and its falility. Signed Intersection Jalan Gatot Subroto - Jalan Veteran Banjarmasin are two traffic flows that are heavily burdened with traffic flow. As in that location it is the main road that connects the Inner Ring Road and A. Yani Road, resulting in high traffic congestion, on the other hand on the road it is difficult to increase in road widening due to the high level of dense residential settlements on the side of the road especially occur at the intersection. This study aims to obtain the level of service at the intersection of Gatot Subroto - Jalan Veteran Banjarmasin. From the calculation results obtained the greatest degree of saturation $(D S) 2.14$, the level of service of the Gatot Subroto Road - Banjarmasin Veterans Road is included in level F, ie at this level the traffic flow is forced, the speed is relatively low, the traffic flow is often stopped resulting in a long vehicle queue of 1540 meters.

Keywords: Signalized Intersection, Traffic, DS, LoS

\section{PENDAHULUAN}

Kota Banjarmasin adalah ibu kota Propinsi Kalimantan Selatan yang merupakan kota industri dan perdaganganan. Hal ini menyebabkan pertumbuhan arus lalu lintas di daerah ini dan daerah sekitarnya meningkat dengan pesat. Pertumbuhan arus lalu lintas saat ini sering menghadapi permasalahan seiring dengan perkembangan kota, pertambahan penduduknya dan pertambahan kendaraan bermotor yang tidak sesuai bila dibandingkan dengan laju pembangunan infrastruktur jalan raya dan falisilitasnya. Alat transportasi yang bergerak bersama-sama akan menimbulkan arus lalu lintas yang terkadang cukup besar, semakin bertambahnya kendaraan yang menggunakan ataupun melewati jalan maka akan menimbulkan suatu masalah lalu lintas yang rumit dalam memecahkannya. Dimana berbagai macam kendaraan seperti becak, sepeda, sepeda motor, mobil truk dan sebagainya. Hal tersebut perlu mendapat perhatian karena ketidakteraturan, kemacetan, dan antrian panjang sering terjadi terutama pada jam-jam sibuk seperti pagi dan siang hari. Salah satu lokasi yang perlu diperhatikan adalah persimpangan Jalan Gatot Subroto - Jalan Veteran Banjarmasin. Karena 
persimpangan merupakan dua arus lalu lintas sehingga jalan terbebani arus lalu lintas yang cukup besar. Seperti pada lokasi tersebut merupakan jalan utama yang menghubungkan antara Jalan Lingkar Dalam dan Jalan A.Yani, sehingga mengakibakan kemacetan lalu lintas yang tinggi maka kondisi nya tidak layak, di sisi lain pada jalan tersebut sudah sulit untuk ditingkatkan dalam pelebaran jalan dikarenakan tingkat pemukiman penduduk padat pada sisi jalan terutama terjadi pada persimpangan. Dalam menyikapi pertumbuhan serta perkembangan kedepan dimana salah satu faktor yang sangat terkait dengan perkembangan suatu kota, yaitu keamanan, kenyamanan, dan kelancaran arus lalu lintas serta sebaik apa tingkat pelayanannya maka dilakukan upaya untuk mengurangi kemacetan lalu lintas dan meningkatkan tingkat pelayanan dengan beberapa cara meningkatkan kapasitas jalan yaitu dengan mengurangi kepadatan volume lalu lintas.

\section{TINJAUAN PUSTAKA}

Perhitungan dilakukan persatuan jam untuk satu atau lebih periode misalnya didasarkan pada kondisi arus lalu lintas rencana pada jam-jam sibuk pagi, siang, dan sore. Arus lalu lintas (Q) untuk setiap gerakan (belok kiri $=$ QLT dan belok kanan = $\mathrm{QRT}_{\mathrm{RT}}$ di konfersikan dari kendaraan perjam menjadi satuan mobil penumpang (emp) untuk masing-masing pendekat terlindung dan terlawan. Untuk menentukan ekivalen mobil penumpang dapat dlihat pada Tabel 1.

Tabel 1. Ekivalen Mobil Penumpang

\begin{tabular}{|c|c|c|}
\hline Jenis kendaraan & $\begin{array}{c}\text { emp untuk tipe } \\
\text { pendekat } \\
\text { (Terlindung) }\end{array}$ & $\begin{array}{c}\text { emp untuk tipe pendekat } \\
\text { (Terlawan) }\end{array}$ \\
\hline Kendaraan Ringan (LV) & 1.0 & 1.0 \\
\hline Kendaraan Berat (HV) & 1.3 & 1.3 \\
\hline Sepeda Motor (MC) & 0.2 & 0.4 \\
\hline
\end{tabular}

Sumber: Manual Kapasitas Jalan Indonesia (1997)

Kapasitas dari suatu pendekat simpang bersinyal dapat dinyatakan sebagai berikut: $C=S \times g / c$

di mana $C$ adalah kapasitas (smp/jam); $S$ adalah arus jenuh, arus berangkat rata-rata dari antrian dalam pendekat selama sinyal hijau (smp/jam); $G$ adalah waktu j=hijau 
(detik); dan Co adalah waktu siklus, selang waktu untuk urutan perubahan sinyal yang lengkap (antara dua awal hijau yang berurutan pada fase yang sama). Dapat dinyatakan sebagai hasil perkalian dari arus jenuh dasar (So) yaitu arus jenuh pada keadaan standar, dengan faktor penyesuaian (F) untuk penyimpangan dari kondisi sebenarnya dari suatu kumpulan kondisi-kondisi (ideal) yang telah ditetapkan sebelumnya.

$S=F 1 \times F 2 \times F 3 \times F 4 \times \ldots \ldots \times F n$

Perhitungan derajat kejenuhan dilakukan sebagai berikut:

$S=Q / C$

Tabel 2. Tingkat Pelayanan

\begin{tabular}{|c|c|c|}
\hline $\begin{array}{c}\text { Tingkat } \\
\text { Pelayanan }\end{array}$ & $\begin{array}{c}\text { Derajat } \\
\text { kejenuhan }\end{array}$ & $\begin{array}{c}\text { Hambatan } \\
\text { Berhenti } \\
\text { (detik/kendaraan) }\end{array}$ \\
\hline A & $\leq 0,35$ & $<5$ \\
\hline B & $\leq 0,54$ & $5,1-15$ \\
\hline C & $\leq 0,77$ & $15,1-25$ \\
\hline D & $\leq 0,93$ & $25,1-40$ \\
\hline E & $\leq 1,0$ & $40,1-60$ \\
\hline F & $>1,0$ & $>60$ \\
\hline
\end{tabular}

Jumlah rata-rata antrian smp pada awal sinyal hijau (NQ) dihitung sebagai jumlah smp yang tersisa dari fase hijau sebelumnya $\left(\mathrm{NQ}_{1}\right)$ ditambah jumlah smp yang datang selama fase merah $\left(\mathrm{NQ}_{2}\right)$ :

$\mathbf{N Q}=\mathrm{NQ}_{1}+\mathrm{NQ}_{2}$

dengan:

$\mathrm{NQ}_{1}=0,25 \times \mathrm{C} \times\left\lfloor(\mathrm{DS}-1)+\sqrt{(\mathrm{DS}-1)^{2}+8 \mathrm{x}(\mathrm{DS}-0,5) / \mathrm{C}}\right\rfloor$

Jika DS > 0,5; selain dari itu NQ1=0 
$\mathrm{NQ}_{2}=\mathrm{c} \times \frac{1-\mathrm{GR}}{1-\mathrm{GR} \times \mathrm{DS}} \times \frac{\mathrm{Q}}{3600}$

Dimana:

$\mathrm{NQ}_{1}=$ jumlah smp yang tertinggi dari fase hijau sebelumnya

$\mathrm{NQ}_{2} \quad$ = jumlah smp yang datang selama fase merah

DS = derajat kejenuhan

GR = rasio hijau

$\mathrm{c} \quad=$ waktu siklus

$\mathrm{C} \quad=\operatorname{kapasitas}(\mathrm{smp} / \mathrm{jam})=\operatorname{arus}$ jenuh kali $\operatorname{rasio}$ hijau $(\mathrm{S} \times \mathrm{GR})$

Q = arus lalu lintas pada pendekat tersebut (smp/det)

Untuk keperluan perencanaan, manual memungkinkan untuk penyesuaian dari nilai rata-rata ini ketingkat peluang pembebanan lebih yang dikehendaki. Panjang antrian (QL) diperoleh dari perkalian (NQ) dengan luas rata-rata yang dipergunakan per smp $\left(20 \mathrm{~m}^{2}\right)$ dan pembagian dengan lebar masuk.

$$
\mathrm{QL}=\mathrm{NQ}_{\max } \times \frac{20}{\text { Wmasuk }}
$$

\section{METODE PENELITIAN}

Tahapan-tahapan penelitian sebagai berikut :

1. Sampel penelitian yang digunakan adalah arus lalu lintas pada persimpangan Jalan Gatot Subroto-Veteran. Data yang digunakan dalam penelitian ini bersumber data primer dan data sekunder. Data primer yaitu data yang diperoleh dengan melakukan langsung pengumpulan di lokasi yang menjadi objek penelitian sedangkan data sekunder berupa data dan dokumentasi yang ada sebelumnya melalui instansi terkait. Data ini sifatnya memberikan gambaran umum daerah penelitian, seperti data geografis, peta jaringan jalan, pertumbuhan kendaraan bermotor, jumlah penduduk, dan informasi lain yang berhubungan dengan kelengkapan penelitian ini.

2. Pengambilan data profil jalan, yaitu: untuk mengidentifikasi karateristik prasarana jalan antara lain panjang jalan, lebar, kondisi, dan juga fasilitas perlengkapan jalan dengan pertimbangan bahwa komponen tersebut dapat mempengaruhi kapasitas jalan. 
3. Pengumpulan data arus lalu lintas, data lalu lintas didapat dari data primer.

4. Untuk memproses data yang didapat, dilakukan dengan menggunakan alat bantu berupa seperangkat komputer dengan paket program Microsoft Excell serta dilakukan pemilahan data untuk mendapatkan komposisi kendaraan yang menggunakan ruas-ruas jalan yang ditinjau. Hasil data yang telah diolah dikelompokkan sesuai dengan jenis atau kelompok masing-masing data yang disajikan dalam bentuk kelompok data yang didapat. Selanjutnya, data dari traffic counting diolah menjadi data arus lalu lintas per jam untuk mendapatkan volume dalam smp/jam.

\section{Diagram Alir Penelitian}

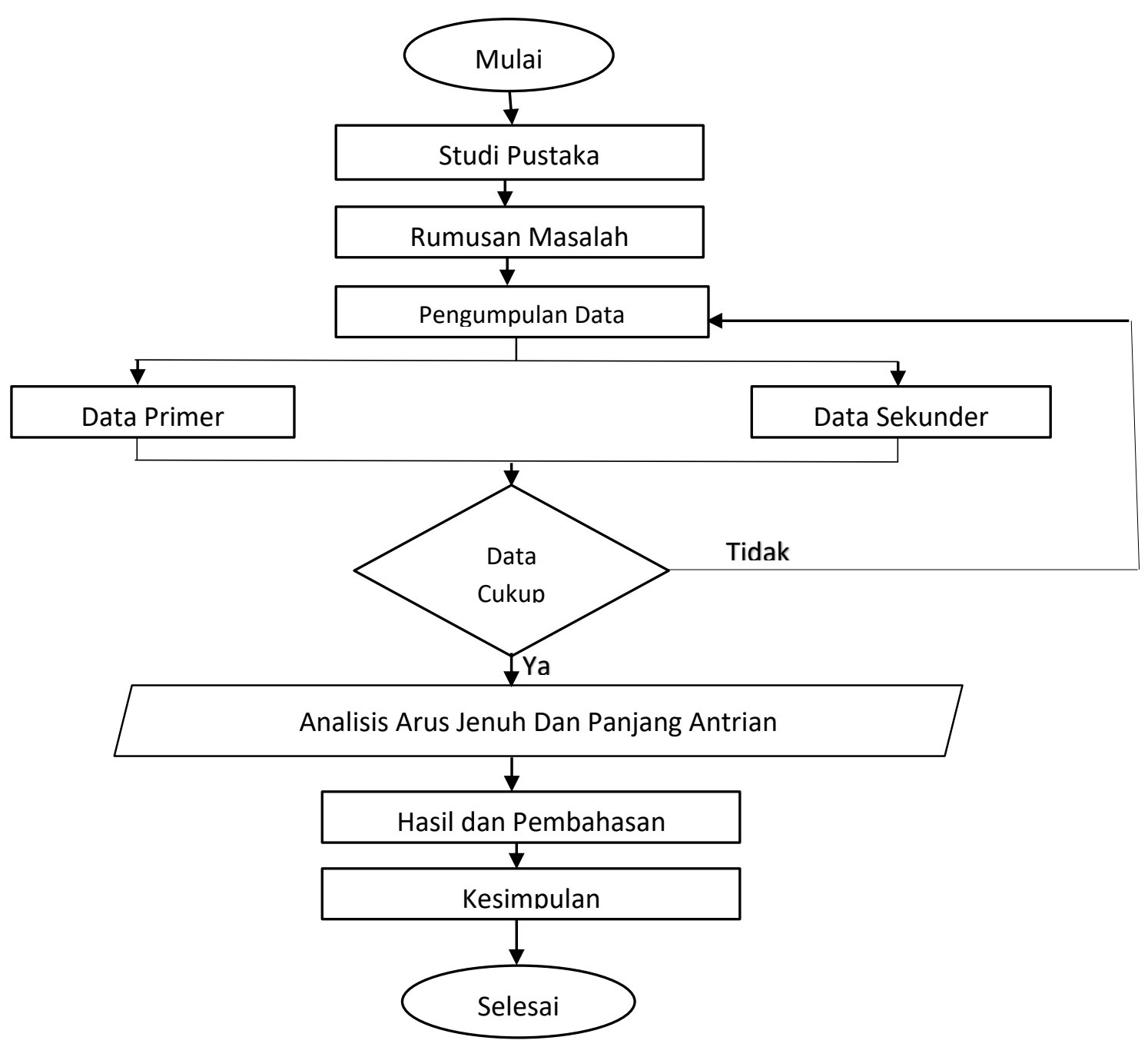

Gambar 1. Diagram Alir Penelitian 


\section{HASIL DAN PEMBAHASAN}

Perhitungan dilakukan berdasarkan langkah-langkah yang diberikan oleh MKJI 1997 keadaan dilapangan dari data-data yang didapat. Dalam hal ini diambil kasus untuk kinerja simpang 4 bersinyal. Data lalu lintas didapat dari hasil survai traffic counting, data yang digunakan adalah data hasil survei pada tanggal 23 Januari 2020 karena volume lalu lintas terbesar terjadi pada hari itu. Untuk menentukan volume kendaraan maksimum dalam per jam maka dapat dilakukan dengan mencari kombinasi yang tepat dari interval waktu yang ada sesuai dengan hasil penelitian yang telah dilakukan.

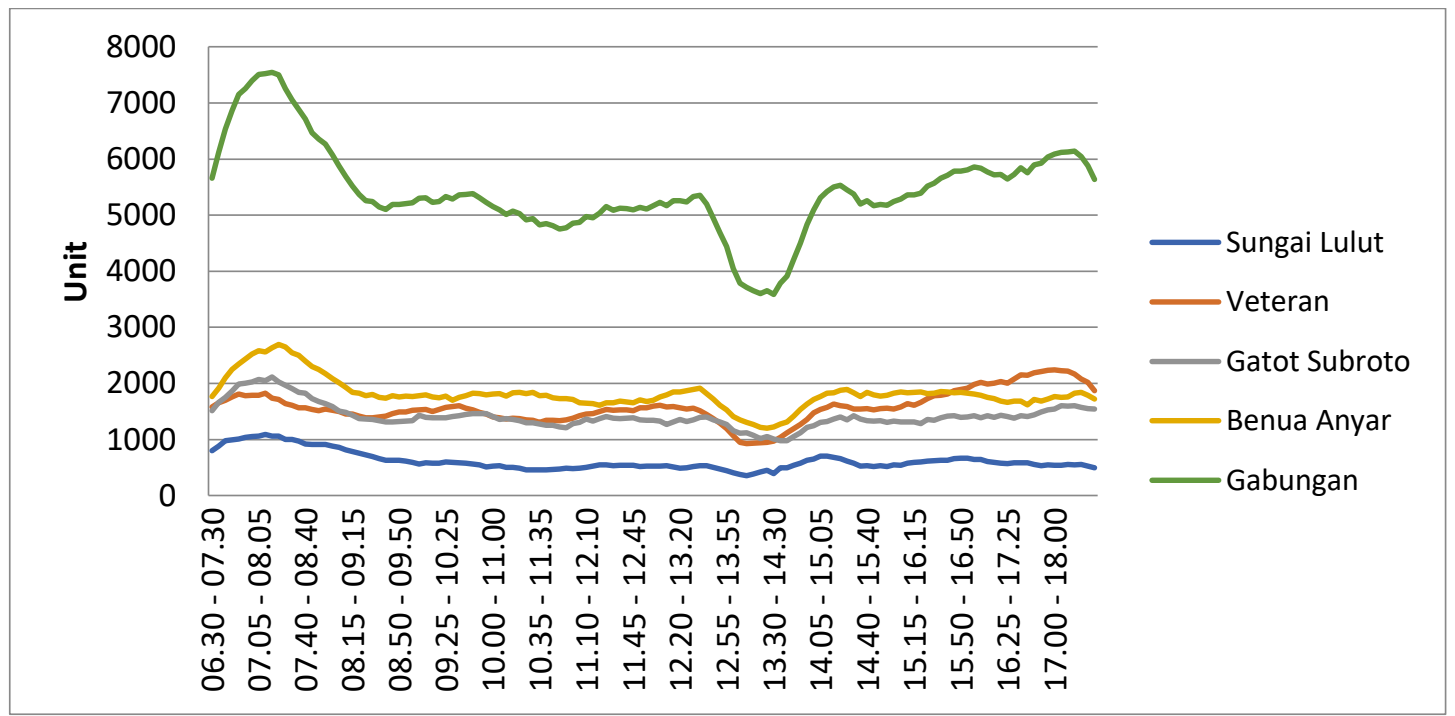

Gambar 2. Grafik Volume Lalu Lintas 
Tabel 3. Jam Puncak Volume Lalu Lintas

\begin{tabular}{|c|c|c|c|}
\hline Periode & Arus Terbesar & Jam Puncak & Volume \\
\hline \multirow{5}{*}{ Pagi } & Lengan Sungai Lulut & $07.10-08.10$ & 1089 \\
\hline & Lengan Gatot Subroto & $07.15-08.15$ & 2113 \\
\hline & Lengan Veteran & $07.10-08.10$ & 1826 \\
\hline & Lengan Benua Anyar & $07.20-08.20$ & 2697 \\
\hline & Total Seluruh Lengan & $07.15-08.15$ & 7725 \\
\hline \multirow{5}{*}{ Siang } & Lengan Sungai Lulut & $09.35-10.35$ & 588 \\
\hline & Lengan Gatot Subroto & $09.45-10.45$ & 1462 \\
\hline & Lengan Veteran & $09.35-10.35$ & 1601 \\
\hline & Lengan Benua Anyar & $12.35-13.35$ & 1912 \\
\hline & Total Seluruh Lengan & $09.45-10.45$ & 5383 \\
\hline \multirow{5}{*}{ Sore } & Lengan Sungai Lulut & $14.05-15.05$ & 705 \\
\hline & Lengan Gatot Subroto & $17.05-18.05$ & 1603 \\
\hline & Lengan Veteran & $17.00-18.00$ & 2239 \\
\hline & Lengan Benua Anyar & $14.25-15.25$ & 1895 \\
\hline & Total Seluruh Lengan & $17.15-18.15$ & 6144 \\
\hline
\end{tabular}


Pada simpang empat Jalan Gatot Subroto - Jalan Veteran ini mempunyai 4 (empat) fase sinyal pada kondisi eksisting, dapat dilihat pada tabel berikut:

0

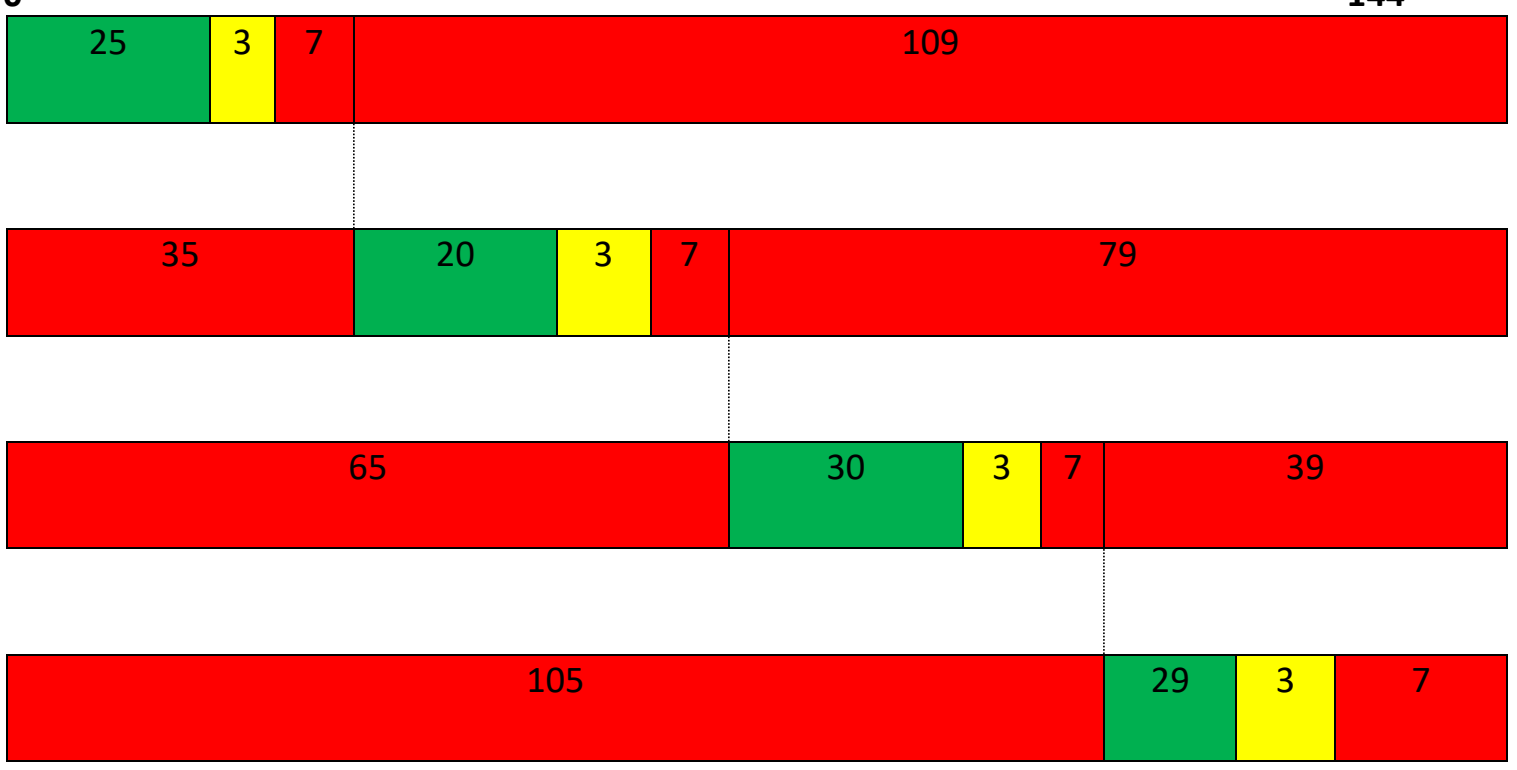

Gambar 3. Waktu Sinyal Kondisi Eksisting

Jumlah fase lampu lalu lintas pada simpang empat Jalan Gatot Subroto - Jalan Veteran, yaitu:

1. Fase (1): - Waktu hijau (g) = 25 detik

- Waktu antar hijau (IG) = 7 detik

2. Fase (2): - Waktu hijau (g) = 20 detik

- Waktu antar hijau (IG) = 7 detik

3. Fase (3): - Waktu hijau (g) = 30 detik

- Waktu antar hijau (IG) = 7 detik

4. Fase (4): - Waktu hijau (g) = 29 detik

- Waktu antar hijau (IG) = 7 detik 


\section{Data Kondisi Lingkungan}

Berdasarkan data yang didapat dari lapangan di dapat:

1. Ukuran Kota

2. Kelas Tipe Lingkungan Jalan

3. Kelas Hambatan Samping
700.870 jiwa (BPS, 2019)

Komersial

Tinggi (Berdasarkan MKJI 1997)

\section{Analisa Perhitungan Berdasarkan Kondisi Eksisting}

Perhitungan dilakukan per satuan jam, dengan tipe pendekat tipe P (arus telindung).

Distribusi kendaraan dihitung setiap gerakan belok dengan mengkonversi tipa jenis kendaraan/jam menjadi smp/jam dengan menggunakan ekivalen kendaraan penumpang yang telah ditentukan. Analisis perhitungan yang diambil pada hasil penelitian adalah dari pendekat Benua Anyar pada pukul 07.20 - 08.20 karena merupakan jam puncak volume terbesar diantara pendekat lainnya.

Tabel 4. Distribusi Kendaraan (kend/jam)

\begin{tabular}{|c|c|c|c|}
\hline \multirow{2}{*}{ TIPE KENDARAAN } & \multicolumn{3}{|c|}{ PENDEKAT } \\
\cline { 2 - 4 } & \multicolumn{3}{|c|}{ Benua Anyar } \\
\cline { 2 - 4 } & ST & RT & LTOR \\
\cline { 2 - 4 } & Gatot Subroto & Veteran & Sungai Lulut \\
\hline LV & 191 & 140 & 62 \\
\hline HV & 0 & 0 & 0 \\
\hline MC & 1445 & 430 & 429 \\
\hline TOTAL & \multicolumn{3}{|c|}{52} \\
\hline UM & 20 & 2697 & \\
\hline
\end{tabular}

Data distribusi kendaraan di atas dikonversikan ke dalam satuan smp/jam dengan menggunakan rumus:

$\mathrm{Q}=\mathrm{LV}(1)+\mathrm{HV}(1,3)+\mathrm{MC}(0,4)$

Untuk contoh perhitungan diambil data LHR pada pendekat dari arah Veteran untuk arah lurus (ST), belok kanan (RT), dan belok kiri (LTOR). 
Terlawan: $\quad \mathrm{Q}=393(1)+0(1,3)+2304(0,4)$

$$
\mathrm{Q}=1314.6 \approx 1315 \mathrm{smp} / \mathrm{jam}
$$

\section{Rasio Belok}

Dari perhitungan pada program KAJI didapat data LHR, yaitu:

Tabel 5. Rasio Kendaraan Belok

\begin{tabular}{|c|c|c|c|}
\hline Arah pendekat & P $_{\text {LTOR }}$ & $\mathrm{P}_{\mathrm{LT}}$ & $\mathrm{P}_{\mathrm{RT}}$ \\
\hline $\mathrm{U}$ & 0,65 & - & 0,01 \\
\hline $\mathrm{S}$ & 0,79 & - & 0,10 \\
\hline $\mathrm{T}$ & 0,23 & - & 0,14 \\
\hline $\mathrm{B}$ & - & 0,01 & 0,39 \\
\hline
\end{tabular}

\section{Rasio Kendaraan Tak Bermotor (UM)}

Dari perhitungan pada program KAJI didapatkan total arus kendaraan tak bermotor (UM):

Rasio kendaraan tak bermotor (PUM): $\frac{\mathrm{QUM}(\mathrm{kend} / \mathrm{jam})}{\mathrm{QMV}(\mathrm{kend} / \mathrm{jam})}=0,03$

\section{Perhitungan Waktu Hilang dan Waktu Siklus}

Pengaturan lalu lintas pada simpang Jalan Gatot Subroto - Jalan Veteran mempunyai 4 fase sinyal.

Waktu Hilang $(\mathrm{LTI})=\sum \mathrm{IG}$

Lama Kuning $\quad=$ Fase I + Fase II + Fase III + Fase IV

$$
\begin{aligned}
& =3+3+3+3 \\
& =12 \text { detik }
\end{aligned}
$$

Lama Merah semua = Fase I + Fase II + Fase III + Fase IV

$$
\begin{aligned}
& =7+7+7+7 \\
& =28 \text { detik }
\end{aligned}
$$


Jadi, total waktu hilang $(\mathrm{LTI})=$ merah semua total+waktu kuning total

$$
=28+12=40 \text { detik }
$$

$$
\begin{aligned}
\text { Waktu siklus (c) } & =\sum g+\text { LTI } \\
& =104+40 \\
& =144 \text { detik }
\end{aligned}
$$

\section{Perhitungan Arus Jenuh}

Untuk pendekat terlindung arus jenuh dasar (So) ditentukan sebagai fungsi efektif pendekatan (We).

\section{Pendekat dari arah Benua Anyar}

$$
\begin{aligned}
\mathrm{Wa} & =5,6 \mathrm{~m} \\
\mathrm{We} & =5,6 \mathrm{~m} \\
\text { So } & =\text { We } \times 600 \\
& =5,6 \times 600 \\
& =3360 \mathrm{~m}
\end{aligned}
$$

\section{Faktor penyesuaian:}

a. Kelas tipe lingkungan jalan: komersil.

b. Jumlah penduduk: 700.870 jiwa. Berdasarkan tabel 2.3 Faktor Penyesuaian ukuran kota, maka didapat ukuran kota $\mathrm{Fcs}=0,94$

c. Kelas hambatan samping tinggi.

d. Rasio kendaraan tak bermotor $=0,03$

Berdasarkan tabel 2.4 Faktor penyesuaian hambatan samping dengan tipe fase terlindung didapat $\mathrm{F}_{\mathrm{SF}}=0,916$

e. Kelandaian tidak ada $\left(\mathrm{F}_{\mathrm{G}}\right)$, ditentukan dari gambar 2.4 Faktor penyesuaian untuk kelandaian $\mathrm{F}_{\mathrm{G}}=1,00$

f. Parkir dianggap tinggi $F_{P}=1,00$ 
g. Faktor penyesuaian belok kanan $\left(\mathrm{F}_{\mathrm{RT}}\right)$ ditentukan sebagai fungsi dari rasio kendaraan belok kanan $\mathrm{P}_{\mathrm{RT}}=0,10$ kemudian hasilnya dimasukkan pada gambar 2.6 Faktor penyesuaian untuk belok kanan $\mathrm{F}_{\mathrm{RT}}=1,02$

h. Faktor penyesuaian belok kiri $\left(\mathrm{F}_{\mathrm{LT}}\right)=1,00$

Jadi, nilai arus jenuh:

$$
\begin{aligned}
S=S_{0} \times F_{C S} \times F_{S F} \times F_{G} \times F_{P} \times F_{R T} \times F_{L T} \\
=3360 \times 0,94 \times 0,916 \times 1,00 \times 1,00 \times 1,02 \times 1,00 \\
=2950,96 \approx 2951 \mathrm{smp} / \mathrm{jam}
\end{aligned}
$$

\section{Perhitungan Kapasitas}

Digunakan rumus 2.1 diambil untuk pendekat dari arah Benua Anyar

$\mathrm{C}=\mathrm{S} \times \mathrm{g} / \mathrm{c}$

$=2951 \times 30 / 144$

$=614.79 \approx 615 \mathrm{smp} / \mathrm{jam}$

\section{Perhitungan Derajat Kejenuhan}

Ds $=\mathrm{Q} / \mathrm{C}$

$$
=1315 / 615
$$$$
=2,14
$$

\section{Panjang antrian}

Jumlah kendaraan yang antri (NQ)

$$
\begin{aligned}
\mathrm{NQ} & =\mathrm{NQ} 1+\mathrm{NQ} 2 \\
& =353,82+76,72 \\
& =430,54=431 \text { kendaraan }
\end{aligned}
$$

Panjang antrian (QL)

$$
\begin{aligned}
\mathrm{QL} & =\mathrm{NQ}_{\max } \mathrm{x} \frac{20}{\text { Wmasuk }} \\
& =431 \times 20 / 5,6 \\
& =1539,28 \approx 1540 \mathrm{~m}
\end{aligned}
$$




\section{PENUTUP}

\section{Kesimpulan}

Dari perhitungan pada simpang bersinyal dengan 4 fase didapatkan derajat kejenuhan (DS) terbesar adalah 2,14 jadi didapatkan indeks tingkat pelayanan (ITP) termasuk dalam level $\mathrm{F}$ yaitu pada tingkat pelayanan ini arus yang dipaksakan atau macet, kecepatan rendah, volume dibawah kapasitas. Antrian panjang dan terjadi hambatanhambatan yang besar. Hal ini dapat terlihat dilapangan bahwa yang antri pada lengan mengalami beberapa siklus sampai dapat keluar dari konflik. Begitu pula arus belok kiri maupun terus dan belok kanan terjadi konflik pada saat sinyal merah sehingga mengakibatkan panjang antrian sebesar 1540 meter.

\section{Saran-saran}

Seiring dengan pertumbuhan penduduk, maka volume lalu lintas juga akan bertambah, sehingga disarankan agar perencanaan tersebut ditinjau kembali berdasarkan:

1. Angka pertumbuhan lalu lintas untuk jangka waktu panjang (beberapa tahun kedepan).

2. Perlu analisis lebih lanjut dengan memperhatikan perubahan geometrik jalan dan perubahan waktu siklus.

\section{Ucapan Terimakasih}

Penulis mengucapkan terimakasih kepada kawan-kawan dosen Uniska MAB serta semua pihak yang telah banyak membantu kelancaran dan selesainya penelitian ini. 


\section{DAFTAR PUSTAKA}

Direktorat Pembangunan Jalan Perkotaan(1997). Manual Kapasitas Jalan Indonesia(MKJI) 1997. Direktorat Jenderal Bina Marga. Jakarta.

Hudoyo, Rosid(2006). Efisiensi Rencana Fly Over Kalibanteng Kota Semarang Dalam Mengatasi Kemacetan Dari Sisi Pengguna. Tesis Program Pascasarjana Program Studi Teknik Sipil. Universitas Diponegoro. Semarang.

Jotin Khristy, C \& Kent Lall,,B (2005). Dasar-Dasar Rekayasa Transportasi. Erlangga. Jakarta.

L.Hendarsin, Shirley(2000). Perencanaan Teknik Jalan Raya.Nova.Bandung.

Saodang, Hamirhan(2004). Konstruksi Jalan Raya.Nova.Bandung

Radam.F,Iphan(2008).Rekayasa Lalu Lintas. Universitas Lambung Mangkurat Press.Banjarmasin. 